\title{
i-SEGOPubmed: a web interface for semantic enabled browsing of PubMed using Gene Ontology
}

\author{
Mohammed Yeasin*1, Bhanu C Vanteru1 ${ }^{1}$, Jahangheer S Shaik ${ }^{2}$ and \\ Faruk Ahmed ${ }^{1}$
}

\begin{abstract}
Address: ${ }^{1}$ Department of Electrical and Computer Engineering, University of Memphis, Memphis, TN 38152, USA and ${ }^{2}$ Department of Pathology and Immunology, Washington University in St. Louis, St. Louis, MO 63110, USA

Email: Mohammed Yeasin* - myeasin@memphis.edu

* Corresponding author
\end{abstract}

from UT-ORNL-KBRIN Bioinformatics Summit 2008

Cadiz, KY, USA. 28-30 March 2008

Published: 8 July 2008

BMC Bioinformatics 2008, 9(Suppl 7):P20 doi:10.1 186/I47|-2105-9-S7-P20

This abstract is available from: http://www.biomedcentral.com//47/-2 105/9/S7/P20

(C) 2008 Yeasin et al; licensee BioMed Central Ltd.

The rapid progress in bioinformatics and functional genomics lead to a vast amount of scientific literature. PubMed is one of the leading repositories and has approximately 20 million abstracts. Browsing such a huge repository to find relevant information as well as providing elearning service requires new generation of interfaces. Methods such as GOPubmed are using keyword-based techniques. Keyword-based search methods often yield results that are not meaningful to the query. This problem can be partially addressed using a semantic enabled interface for browsing and information retrieval.

A web interface called i-SEGOPubmed is being developed in CVPIA lab at the University of Memphis. i-SEGOPubmed enables semantically meaningful browsing of large volume of semi-structured data such as Pubmed using Gene Ontology. i-SEGOPubmed employs a clientserver computing model. The SEGOPubmed engine [1] is used to process queries and web interface is using the Java Web Start, which uses Java Network Launching Protocol (JNLP) for downloading the application from the server to the client. Once the application is downloaded, Java Web Start initializes the application to check for the local resources. i-SEGOPubmed requires JRE (Java Runtime Environment) for its execution. It uses the Java Sockets to establish a data communication between the interface running on the client machine and the query processing done on the server machine. The server machine has a dedicated Server Socket listening to client requests. Once the server receives a request, it initializes a full duplex communication channel between the server and the client machine. Using this data channel, the interface sends the query to the server for further processing. Figure 1 shows the system architecture and the information flow of the proposed i-SEGOPubmed.

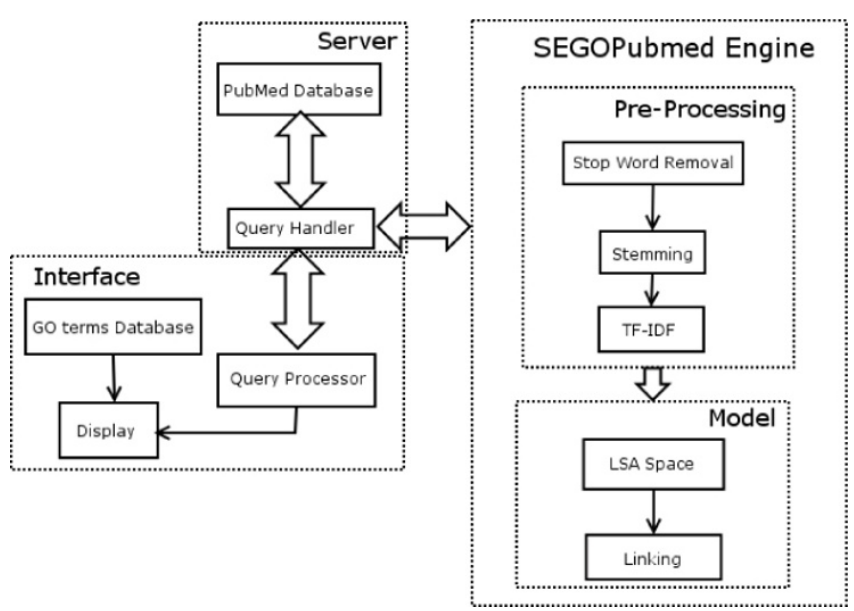

Figure I

Schematic diagram and information flow of the proposed iSEGOPubmed. 


\section{References}

I. Vanteru BC, Shaik JS, Yeasin M: Semantically linking and browsing PubMed abstracts with gene ontology. BMC Genomics 2008, 9(SuppI I):SIO.

Publish with Bio Med Central and every scientist can read your work free of charge

"BioMed Central will be the most significant development for disseminating the results of biomedical research in our lifetime. " Sir Paul Nurse, Cancer Research UK

Your research papers will be:

- available free of charge to the entire biomedical community

- peer reviewed and published immediately upon acceptance

- cited in PubMed and archived on PubMed Central

- yours - you keep the copyright 